\title{
Geodesign Processes and Ecological Systems Thinking in a Coupled Human-Environment Context: An Integrated Framework for Landscape Architecture
}

\author{
Yexuan $\mathrm{Gu}^{1, *}$, Brian Deal ${ }^{1}$ (1) and Linda Larsen ${ }^{2}$ \\ 1 Department of Landscape Architecture, University of Illinois at Urbana Champaign, \\ Champaign, IL 61820, USA; deal@illinois.edu \\ 2 Smart Energy Design Assistance Center, University of Illinois at Urbana Champaign, \\ Champaign, IL 61820, USA; lflarsen@illinois.edu \\ * Correspondence: ygu23@illinois.edu; Tel.: +1-509-715-7576
}

Received: 18 July 2018; Accepted: 4 September 2018; Published: 15 September 2018

\begin{abstract}
Scholars from a variety of disciplines have been working to unravel the complexities of geodesign as an approach to tackling a host of problems. We argue that a mature understanding of geodesign requires a systemic perspective to organize the interconnections between ecological, social and economic conditions at multiple spatial and temporal scales. We reviewed definitions and perspectives of geodesign and key concepts of ecological systems thinking to develop a new framework for landscape architecture. We provide the state-of-the-art in geodesign within the context of systems thinking and coupled human-environmental resilience. We show that geodesign is capable to encourage public participation and interdisciplinary collaboration through its systemic planning processes and synergetic technologies. The thrust of geodesign-related research is the emerging paradigm of landscape-based sustainability. While landscape architecture is complex in many aspects, the integrated framework promotes our understanding about its social-ecological potential, spatial-temporal association and resilience of coupled human-environment systems. Based on the findings, we outline key contributions, implications, challenges and recommendations for future research.
\end{abstract}

Keywords: sustainable design; geodesign; systems thinking; social-ecological processes; spatial-temporal patterns; human-environment systems; landscape-based sustainability

\section{Introduction}

Geodesign has been described as a set of processes and technologies used to collaboratively design for a broad range of the complex and interconnected spatial challenges inherent in the built and natural environment [1]. It uses a systems-based procedural approach that explains the interrelationships between human and environment systems at multiple scales to provide useful information for design and decision support. Over the last decade, geodesign has gained increasing momentum [2-4]. Despite a broad acknowledgement of its utility in design and connection to systems analysis, the literature on geodesign, especially from the lens of ecological systems thinking in landscape architecture, is still somewhat fragmented [5]. Additionally, a commonly accepted, comprehensive and theoretically strong definition of geodesign for landscape architecture has yet to be established.

A systematic review of the geodesign literature and an exploration of its connection to ecological systems thinking can benefit not only designers and planners but scholars in many fields (e.g., geographers, engineers, policy makers and ecologists, among others). A core strength is that the process encourages a multidisciplinary approach with explicit questions that scrutinize targeted issues 
from multiple perspectives (i.e., landscape urbanism, strategic design, ecosystem services, natural capital, geological survey, stakeholders and facilities). The connection between geodesign processes and ecological systems thinking can help clarify the complex interconnectivity between ecological, social and economic issues that make up a landscape and assist in the development of more robust design solutions.

This paper is neither a literature review nor a historical narrative. Instead, we provide an overview of the state of geodesign within the context of coupled human-environmental problems. We review the existing literature to explore how current geodesign-based studies define and utilize the concept. More specifically, we systematically identify influential articles, search the theoretical origins and evolution of geodesign-based studies and analyze the idea of geodesign across multiple disciplines. In the process, we identify four major themes: (1) geodesign as a geography-centered multidisciplinary science, (2) geodesign as an iterative design process, (3) geodesign as a community participatory planning tool and (4) geodesign as a process for exploring landscape-based sustainability-oriented ideas. We use these perspectives to help reveal an overall basic theoretical structure and a synergetic definition of geodesign. We then illustrate core concepts of ecological systems thinking to explore the systemic connection to geodesign. By integrating geodesign and ecological systems theory, we create a new heuristic framework for landscape architecture. The new framework helps to identify significant variables for studying landscapes and landscape scaled solutions within a coupled human-environmental system. It also provides a common platform for the accumulation of knowledge in this arena. We conclude the paper with remarks on the major findings of this study and recommend future research directions.

\section{Evolving Definitions and Perspectives in Geodesign}

Geodesign first appears in print in a 1993 paper by Klaus Kunzmann titled, "Geodesign: Chance order Gefahr?" [6] and later in multimedia form, with a 2010 TED talk by Jack Dangermond [7]. Carl Steinitz follows with an influential geodesign process framework, "A Framework for Geodesign" that has become an important handbook for both scholars and practitioners [1]. Over the last decade, geodesign has gained increasing momentum in both the research and practice of landscape architecture and urban design $[3,4,8]$. Geodesign has proved useful for a number of reasons. First, it enhances the relationship between Geographic Information System (GIS) and design [9]. It accommodates progressive development through dynamic design processes and advanced geospatial technologies [7]. Geodesign also acknowledges complex socio-environmental systems [10], while improving the effective communication of various value structures from groups including stakeholders, designers, scientists and community members [11-14]. Variations of the geodesign process have been noted as an important tool for designing for the future, especially when used in conjunction with Planning Support Systems (PSS), simulation and optimization models [15-17]. Finally, geodesign has been identified as a useful approach for addressing climate change [18-20].

This paper identifies definitions of geodesign from multiple literature (see Supplementary Materials for a list of definitions from major literature). The broad and complicated array of geodesign uses has resulted in a similarly broad array of disparate and fragmented definitions. Landscape architecture scholar Steinitz [21] defined geodesign as an inclusive term-a framework with 6 essential questions and a collaboration component. From a technological perspective, Ervin [22] described geodesign as an activity of "environmental planning and design that leverages the powers of digital computing, algorithmic processes and communications technologies" and depends upon "timely feedback about impacts and implications of proposals." This clearly emphasizes the significance of technologies for the iterative design process reflecting a procedural approach to simulate and model landscape changes in the future. Similarly, Foster [14] defined geodesign as, "a design process that... engages GIS at several points including using GIS and relevant scientific data to better evaluate and understand the potential consequences of design alternatives." Flaxman [2] notes that "geodesign ... tightly couples the creation of design proposals with impact simulations informed by geographic context, systems thinking and digital technology." In contrast, Campagna [23] argued that "methods 
and tools to be used in the process phases may vary accordingly ... central to geodesign is how to design and manage such complex processes." This reflects the novelty of the geodesign process.

We synthesized the various definitions using a thematical classification approach with deductive codes that emerged from the reviews. These codes are as follows: human-environment systems [24]; geographic sciences [1]; iterative design process [14]; community collaboration [25]; and systems-oriented concepts-hierarchical systems, interconnections, functions, feedback loops, delays and dynamics [26]. In the process four major themes became apparent: (1) geodesign as geography-centered multidisciplinary science, (2) geodesign as an iterative design process, (3) geodesign as a tool for community participatory planning and (4) geodesign as a method for landscape-based sustainability solutions.

\subsection{Geodesign as Geography-Centered Multidisciplinary Science}

In landscape architecture, McHarg was one of the first to encourage collaboration between different disciplines [27]. To that point the field had been "dominated by narrow views and singular values" [3]. McHarg assembled a group of scientists from various disciplines in geographical, biological, social and physical sciences to study landscapes, environment and human's role in natural processes $[3,27,28]$. The work espoused a socially conscious view of nature and a more sensitive approach to designing (and developing) urban systems [28]. The socially oriented perspective of McHarg and his contemporaries was reflective of the social upheaval of the 1960s and 70s worldwide. According to Longley et al. [29], current conceptions of geodesign are taking shape during a similarly disruptive shift, only this time the focus is technology and not social norms. He suggests that massive investment in technologies that advance social and environmental goals with a spatially oriented perspective are disrupting previous ways of viewing the world.

Building on McHarg, Steinitz explores the relationship between "physical form and activity organization" in environmental design [30]. This expanded McHarg's focus on landscape to geography, human ecology, social ecology, urban design and urban planning. At the International Conference on Information Technologies in 2010, Jack Dangermond (CEO of ESRI-the leading GIS software developer in the U.S.) reiterated the multidisciplinary theme by noting that geodesign borrows from a wide variety of domains: architecture, landscape architecture, urban planning, engineering and traditional sciences to form a comprehensive and complementary view of landscape design [7].

Global examples of the 'unbounded' disciplinary relationships in geodesign are numerous [31-34]. Aina, Al-Naser and Garba [33] presents an integrative geodesign approach in the Middle East that cuts across several disciplines: sociology, economy, socio-economy, environmental science and urban design. This integrative approach attempts to resolve the multiple conflicting issues between the values of traditional urban form and modern urban design models. Campagna and Di Cesare [31] provide critical insights from both practical and normative perspectives on ways to bridge the gap between geodesign, planning practices and regulatory structures. Their study, focused on an Italian example, offers a good example of the relationship between multidisciplinary actors, institutions, educators, designers and public administrators and the geodesign process. In China, the Wulingyuan National Scenic Area project used a multidisciplinary geodesign process as a catalyst for improving multidisciplinary education in the region [32].

\subsection{Geodesign as an Iterative Science and Design Process}

A common theme in the geodesign literature is that it integrates science with iterative design processes [1-3]. The integration of science and design has roots in the "design methods movement (DMM)" from the early 1960s and the formation of the Design Research Society (DRS) in 1966. They were formed in the wake of post war techno-optimism and were built on a belief that making design more scientific would help to produce a better world [35]. They also considered 'the nature of research' as an evolutionary account of the design process and the use of case studies as an important method [36]. The DRS remains an international network of design researchers committed to promoting 
and developing design research, which when connected to geo technologies and spatial analysis, forms an important connection to geodesign [37].

Iteration in design is foundational and intrinsic to the creative process. It is also a process that has proven important for tying the science and design disciplines together [38]. Steinitz infuses iterative design with the scientific method using six models to interpret a comprehensive design process: representation models, process models, evaluation models, change models, impact models and decision models. The first three models constitute the assessment of existing conditions within a geographic context. The second three models encompass an intervention process, determining how the context might be changed and the potential consequences of those changes. In the Steinitz process these six models are iterated to explain questions of-what is being studied, why physical processes act the way they do and how they might be modified. Although the Steinitz framework is typically depicted as a linear progression, the process is fundamentally non-linear and iterative [39]. Like a design process, it is a series of, "overlapping spaces rather than a sequence of orderly steps" that can loop back on themselves at multiple points in different phases [18,38].

Scholars view the iterative geodesign process from different perspectives. Foster [14] juxtaposes Steinitz's framework with well-known design theories from five scholars: Simon [40], Asimow [41], Fogler et al. [42], Brown [18] and Kumar [43]. She found significant similarities among them including non-linear steps, the importance of decision-driven goals and the combination of "divergent" steps (collecting disparate information) and "convergent" steps (analyzing and evaluating all relevant information to assist making final decisions). Campagna [23] integrated the iterative process with a Business Process Management (BPM) approach to provide process management and setting requirements for organizing different computational techniques.

\subsection{Geodesign as Community Participatory Planning}

According to Ruggeri and Young [44], community participation in design can simultaneously engage the public in decision making, improve deliberative democracy, promote solidarity practice, encourage social connections across different groups and influence socialization positively in public spaces. As an approach to community participatory design, geodesign requires and provides a wide range of opportunities for community collaboration. The process typically encourages community members and community stakeholders to inform project parameters and goals, participate in consensus building and engage in design negotiation. A number of scholars have demonstrated the importance of community engagement and participation in the geodesign process. Steinitz [30] for example, notes the importance of the role of citizen participation in design. He argues that the efficacy of understanding and affecting environmental conditions should not be underestimated and should be done only to achieve more meaningful spaces for people. Wilson [37] emphasizes that geodesign should gather diverse information from the public to "inspire new geographic literacies and new retentional strategies for engagement."

Community participation in planning has a long history that is intertwined with participatory design concepts [44]. In urban planning, involvement that 'recognizes an active part in plan making' is the most cited definition [45]. In participatory design (or 'cooperative design'), it is seen as a platform for active participation in the design process. There is a subtle but distinct difference. One is focused on participation in a (planning) process, the other is focused on participation in a (design) outcome. In geodesign participation, people have to negotiate. Latour [46] provides four precise tables discussing nature, people of nature and religion to illustrate why it is hard for people to negotiate and how to give negotiation a chance.

Social movements in the U.S. in the 1960s promoted the institutionalization of citizen participation in local (and national) policy decision making processes [47]. This backlash against authoritarian decision making sets in motion the modern conceptions of participatory and shared governance models for decision making (this included design). Putnam [48] uses conceptions of volunteering, voting and other methods of participation in civic life, to coin the term "social capital." Social capital has proven 
an effective way of measuring the networks of relationships among people who live and work in a particular place and their willingness to participate in bottom-up design and decision processes [49,50].

More recently, community participatory design has been enhanced with the development of social media related technologies that can gather information about residents and their daily habits and activities to inform design. Zhou et al. [51] use smartphones to determine travel behavior. Campagna (2014) introduces Social Media Geographic Information (SMGI) to gather social media information from diverse sources and Spatial-Temporal Textual Analysis (STTx) to explore perceptions of the environment both spatially and temporally. In design practice, Moran et al. [52] integrate a series of techniques for community participation in a creek revitalization project in Syracuse, New York. $\mathrm{Wu}$ and Chiang [53] describe a geodesign workshop where they use an interactive 3D urban design platform to compile people's ideas, to communicate and to interact. Other approaches include 'beyond text' tools such as storytelling, performance, art and photography [54]; community mapping [55]; participatory design [56]; participatory co-modeling [57,58]; participatory evaluation [59,60]; and synthesizing, downscaling and visualizing alternative futures [52,61].

\subsection{Geodesign as Methodology for Landscape-Based Sustainability}

The above perspectives of geodesign are generally in line with the four categories laid out by Steinitz [1] (geographic sciences, design professions and the people of the place). One exception however, is 'information technologies.' We argue that information technologies are securely embedded in the other three categories and it need not be given separate attention. We also argue that information technologies have become so endemic to design and the design process that they are no longer unique to specific geodesign processes (they are everywhere all the time). In our conception, we replace 'technologies' with 'landscape-based sustainability,' for a fourth category aimed at a targeted outcome from the application of geodesign processes.

Ongoing urban studies suggest a landscape-based paradigm. Waldheim [62] demonstrates the importance of landscape as model and medium for contemporary cities and creates a general theory for understanding landscape urbanism. This new paradigm is also reflected in geodesign. We use Wu's conception of urban ecology [24] to help explain the basis of our Geodesign framework. Wu uses a triad of spatio-temporal patterns, urban sustainability and human environmental impacts. We build on that to present three categories for the resolution of complex human-environment system problems (Figure 1). As the figure shows, geodesign uses representation systems to provide actionable spatial knowledge to visualize spatiotemporal patterns for general urban sustainable analysis. Using Planning Support Systems (PSS) and an iterative process, geodesign analyzes spatiotemporal patterns to generate models and to simulate their impacts on human and environment systems. Through Information and Communication Technology (ICT), community participation of geodesign helps people experience the iterative geodesign process and gain ethical and scientific understanding of sustainability. Using Representation Systems, such as GIS and GeoPlanner, we visualize multidisciplinary scientific information within geographical context to make the complex science understandable for people from different fields and communicate with each other efficiently. All these elements and interrelationships of geodesign and landscape studies ultimately lead to landscape-based sustainability. Geodesign provides benefits to participants through the collaboration of these perspectives, linking the three poles of landscape architecture. 


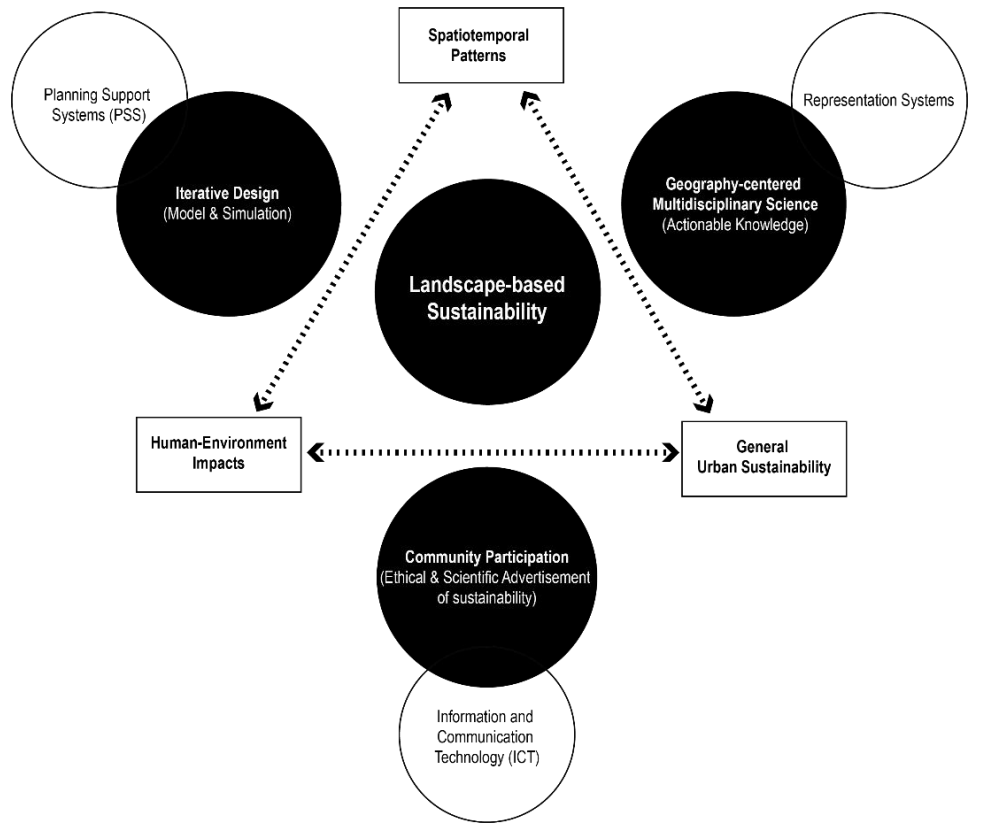

Figure 1. A triadic conceptualization of contemporary landscape studies and the relations with the four geodesign elements through different technologies.

\subsection{Connecting to Landscape Studies}

As Figure 2 shows, geography-centered multidisciplinary science emphasizes the spatial changes of environmental systems. Iterative design integrates systems thinking and creative design processes to emphatically explore the temporal changes of environment systems and the impacts of the changes on human beings. These two aspects incorporate to primarily investigate spatiotemporal patterns and processes of environment systems. Community participation integrates the social, cultural and economic dimensions with the ecological considerations of geodesign [63]. It emphasizes the socio-spatial patterns of human systems at multiple scales (neighborhood, city, metropolitan area, regional area). By cooperating with iterative design, community participation can be expanded to investigate both spatiotemporal patterns and processes. Landscape-based sustainability treats cities as coupled human-environment systems, with increasing emphases on spatiotemporally heterogeneous, multi-scaled landscapes [64-67]. Each aspect has its own emphasis, while they can be incorporated effectively to address broad-scale problems in real landscapes by simultaneously considering spatiotemporal patterns and processes in coupled human-environment systems.

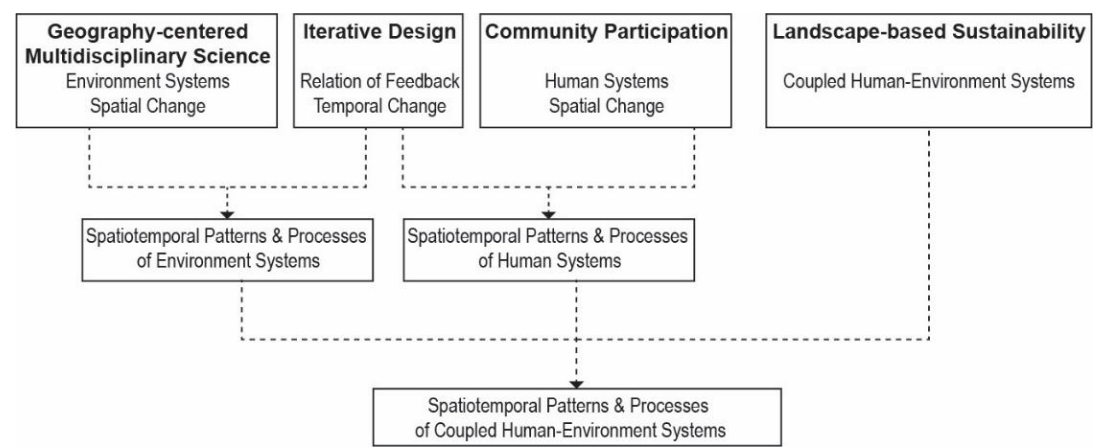

Figure 2. Our conception of the four aspects of geodesign and how they function differently and interrelate each other to facilitate geodesign within coupled human-environment systems.

This perspective of landscape-based sustainability has various benefits. According to Agnoletti [68], the landscape-based approach integrates environmental, social and economic factors, making landscape 
a new paradigm for the local sustainable development model. This reflects a widely adopted human-environment systems perspective in the study of sustainable development. Forman [69] emphasizes that landscapes function as collaborative platforms for planners, designers, geographers, ecologists, social scientists and engineers to "mold the land so nature and people both thrive long term." Planners, designers and geographers have long considered urban places as landscapes of different scales that encompass patches, corridors and matrices [70]. However, multidisciplinary collaborations that use landscape ecology based approaches (e.g., hierarchical patch dynamics) are in their infancy. Zonneveld [71] uses the approach to describe the landscape as a comprehensive set of dynamic relationships between ecological, social and economic factors. From a procedural perspective, Cerreta et al. [72] notes that a landscape should be considered a process that is constantly changing based on social and ecological practices.

\section{Core Concepts of Ecological Systems Thinking}

Systems thinking is a useful lens for understanding the underlying theoretical mechanism of geodesign. In this section, we describe the core concepts of ecological systems thinking (hierarchy, adaptability and resilience, the adaptive cycle, connectedness and incorporation, panarchy, innovative potential, emergence and self-organization and feedback) and their relationship to geodesign studies. In Supplementary materials (Table S2), as an example, we particularly investigate the systemic basis of Steinitz [1]'s six models (representation model, process model, evaluation model, change model, impact model and decision model) which are commonly accepted as standard geodesign processes. For each model, we have provided a short description with corresponding systems-thinking concepts. Hierarchy. Hierarchy theory offers a framework from which to view and integrate different scales. Three dimensions are considered: time, space and organization, which are often viewed as nested hierarchies [73]. For example, atoms are organized into molecules, molecules into cells, cells into organs, organs into individuals, individuals into populations, populations into communities and communities into ecosystems. Lower organizational levels operate in smaller partitions of space and shorter periods of time. Thus individuals operate on small scales in time and space, while ecosystems operate on much larger scales in time and space [74]. This simple concept can help in the identification of similar functional elements and spatial scale properties in the landscape. For example, a human may live 75 years, a building 100 years, human communities have been known to exist for centuries, and a landscape can survive millenniums.

The value of ecological systems thinking in geodesign derives from the hierarchical nature of complex systems [75], where conflicts and contrasts emerge with more hierarchical levels. Geodesign participants are responsible to negotiate and balance the conflicts and self-beneficial tendencies of different organizations, as well as to recognize and take their responsibilities within larger socioeconomic systems [76]. Understanding hierarchy is significant for participants to conceptualize the complex multi-level systems and prioritize design needs without being entangled in ambiguous and dispersed thoughts.

Adaptability and Resilience. Resilience or adaptability represents the ability of systems to survive a perturbation and maintain their desired structure [26]. In his seminal work in systems ecology, Holling [77] defined resilience as the capacity of a system to tolerate disturbance without collapsing into a qualitatively different state. From an urban systems perspective, resilience is often used to describe the capacity of urban environments to withstand the influence of a massive disturbance (disaster), or a changing circumstance (climate) [78]. Understanding the complexity of the system being studied and its dynamic interactions has been noted as one of the important challenges to planning for resilience in a socio-physical (urban) systems context [79].

Recent scholarship has suggested various approaches to planning for resilient places. Fiksel [80] proposes analyzing multiple models simultaneously in order to simulate the idea of redundancy and iteration. In order to counteract the challenge of complexity, Folke et al. [81] argue for a better "understanding of the complex connections between people and nature." Urban researchers have 
developed some basic tenets to describe the dichotomy in planning for urban resilience: redundancy and efficiency, diversity and interdependence, strength and flexibility, autonomy and collaboration and planning and adaptability [78,82-84]. Others espouse a precautionary approach aimed at reducing vulnerability and enhancing resilience in everyday planning activities $[85,86]$. To build the adaptability of a design, geodesign may innovate new design models and transformative learning processes to cope with changes in complex systems $[39,87]$.

The Adaptive Cycle. Gunderson [88],Holling [89] introduced a heuristic model-an adaptive cycle-representing the resilience paradigm of ecological systems theory. It consists of an endogenously driven infinite loop formed by four phases-exploitation $(\mathrm{r})$, conservation $(\mathrm{K})$, release $(\Omega)$, reorganization $(\alpha)$-with three dimensions-potential, connectedness and resilience. The foreloop (from $r$ to $K$ ) is characterized by a long period and incremental growth. In $r$ phase, resources are freely available. Through slow growth and extensive distribution of nutrients and biomass, the connectedness and stability of systems rapidly increase. In $\mathrm{K}$ phase, resources become distributed and sequestered to different components with a slower growth rate. Thence overconnected patterns, rigid structure and intense competition make it vulnerable to collapse. Systems then very rapidly transit into vulnerable $\Omega$ phase, then rapidly to $\alpha$ phase. In $\alpha$ phase, components of the system minimize energy loss and rapidly reorganize themselves to get ready for the next $r$ phase. It may also lead to a transformation of systems into a new state of stability or configuration of landscape with a new foreloop $[90,91]$. The backloop (from $\Omega$ to $\alpha$ ) is characterized by short period, turbulent changes and creative destruction where more opportunities for creative actions can emerge toward renewal [88].

The adaptive cycle is not just a framework to understand the dynamic processes of resilient systems. It also elucidates the innovative opportunities throughout all the phases. Westley et al. [92] advance the adaptive cycle using a model of opportunity context and point out the opportunity of innovations in each phase: (1) in r phase, initiating innovations when increasing investment of new capital supports robust ideas; (2) in K phase, institutionalizing innovations when they are strongly established and disseminated; (3) in $\Omega$ phase, creative destruction when the routine built by the old ideas collapses; and (4) in $\alpha$ phase, exploring new innovations when new ideas are created. To advance desired transformations, people have to find the opportunities hidden in each phase.

Connectedness \& Incorporation. According to hierarchy and panarchy theory, systems result from evolutionary processes that favor both nested, hierarchical organization and dynamic structures with a variety of variables [93]. Levels are typically considered in three levels: the level of the system studied, the next higher level to provide context (constraints) and the next lower level, which contains the dynamics and structure to be modeled-a hierarchical level being studied derives, by incorporation, its constraints from the scale larger and its dynamic interactions from the scale smaller. For example, a disturbance that clears a small section of forest stand is, at one level, a non-equilibrium event-a drastic change has taken place. But the same disturbance incorporated into the landscape level can prove to be an equilibrium behavior; it may have little effect on the overall landscape.

In 1970, Orie Loucks presented a field study of incorporation within increasing temporal scales. He found in the southern Wisconsin forests, a long-term stability of the overall landscape even though random small-scale disturbances (fires) were a regularly occurring phenomena [94]. Integrating geodesign with theories of incorporation, we can associate small-scale design processes with larger scales using appropriate indicators and criteria to facilitate dynamic analysis of systems $[95,96]$. Chrisman [97] documented the historical shift from small-scale to cross-scale landscape planning with the development of comparing maps and spatial data in multiple layers using GIS. With an understanding of the incorporations of heterogeneity and scale multiplicity, geodesign encompasses cross-scale impacts and systems evolutions to facilitate decision making processes.

Panarchy. All systems exist and function at multiple scales. Interactions across scales are fundamentally important in determining the dynamics of the system. This interacting set of hierarchically structured scales has been termed a "panarchy" [98]. A panarchy illustrates a semi-autonomous structure formed from the interactions among multiple variables at multiple time and geographic scales [99]. Similar to 
theories of incorporation, a panarchy framework connects adaptive cycles in a nested hierarchy. There are potentially multiple connections between phases of the adaptive cycle at one level and phases at another. The smaller, faster, nested levels invent, experiment and test, while the larger, slower levels stabilize and conserve accumulated memory of system dynamics. Like incorporation, the slower and larger levels set the parameters in which faster and smaller levels function. Similar to resilience theories, reorganization occurs following phases of destruction, allowing for the establishment of new system configurations and opportunities for the incorporation of an entirely novel system. The adaptive cycle explicitly introduces mutations and rearrangements as a periodic process within each hierarchical level in a way that partially isolates the resulting experiments, reducing the risk to the integrity of the whole structure.

Innovative potential. After a vulnerable system experiences a serious disturbance, increasing uncertainties emerge. To address the uncertainties, scenarios and testing models are introduced to enable the evaluation and comparison between potential future conditions [26]. Scenarios are generally thought of as cogent stories intended to aid decision makers. One typology classifies scenarios as predictive (i.e., forecasts), normative (i.e., preserving, transforming) and explorative (i.e., external and strategic) [100]. Each type of scenario planning requires a different mode of operation. For example, construction of predictive scenarios may involve modeling, whereas normative scenario construction may involve workshops, backcasting, or Delphi methods [87]. Irrespective of motivations and methodologies, however, scenario planning assumes that if decision makers consider multiple futures, they are more likely to make better decisions [101]. Using scenarios and testing models in geodesign, the avalanche of disordered data can be clarified and simplified into a tractable number of clear possibilities $[79,102]$. Scenarios also translate these modeled possibilities into narratives to facilitate communications among multi-disciplinary participants in geodesign processes.

Emergence and self-organization. According to Goldstein [103], emergence is "the arising of novel and coherent structures, patterns and properties during the process of self-organization in complex systems." Referred to as spontaneous order (in the social sciences), self-organization is a process where some form of order emerges from interactions within a previously disordered system. Using geodesign processes, the nature of complex systems can be assessed by investigating how changes in one part affect the others and the behavior of the whole. Thus, systems modeling and simulation can analyze the dynamics and facilitate the emergence of a complex system, which reveals more interactions within the system, increases more options for solutions and ultimately enhance final decisions [87,104,105].

Feedback. Feedback is an important type of interconnection. They are "the secondary effects of a direct effect of one variable on another, they cause a change in the magnitude of that effect. A positive feedback enhances the effect; a negative feedback dampens it" [106]. Forrester [107] relates urban systems to complex systems (i.e., ecosystems) in which positive feedback and other processes influence spatial constructs. He uses dynamic models to describe urban transformation as a process of stagnation, decay and health. According to Forrester:

"Complex systems are counterintuitive. Most of our intuitive responses have been developed from first-order, negative feedback loops where the goal seeking action has one state variable. This helps to link cause and effect with space and time. But cause and effect are not always related to the same space and don't always occur in successional time periods. A complex system has a multiplicity of intersecting feedback loops, controlled by nonlinear relationships. In the complex system the cause of an occurrence may lie far back in time and far away from the symptoms noted. In fact causes are usually found in the policies and structure of the system" [107].

In Forrester's view higher-order complex systems require more intricate analysis that assesses localized cause-and-effect relationships from a global, higher-order perspective. Using this approach, in geodesign, we realize the importance of people's responses toward the feedback loops. When we respond positively to the feedback loops through proper strategies, the larger systems can be advanced across multiple scales. When we fail to understand the feedback loops, the systems may become vulnerable to disaster [108]. 


\section{Integrating Geodesign with Ecological Systems Thinking: A Heuristic Framework}

Ecological systems thinking is a useful lens for exploring the underlying theoretical structure of geodesign and landscape architecture within a coupled human-environment system. As noted above, geodesign is a procedural approach that systemically analyzes, evaluates and makes changes to the landscape by investigating the interrelationships between different systems across time and space. Its procedural framework also helps discern the latent opportunities hidden in other systems or scales by examining systems hierarchy, interactions and feedback controls. By integrating our geodesign framework with Gunderson's adaptive cycle, a new heuristic framework evolves that can help us understand landscape dynamics in complex, coupled human-environment systems (Figure 3).

In our reconceived adaptive cycle framework, a "process analysis" identifies the significant systems elements and their processes in the studied landscape. It helps define the inherent hierarchies and panarchies that help determine scales and system interconnections. Geodesign participants negotiate and balance the conflicts and self-beneficial tendencies of different organizations with their benefits within larger socioeconomic systems [76]. Hierarchy and panarchy theories help to conceptualize the complex multi-level systems and prioritize design needs. We also investigate the dynamic processes from $r$ to $\mathrm{K}$ and interconnections among the accumulated landscape features. Multiple processes may be identified in multiple levels: storage, accumulation, sequestration, competitive processes and so forth. Incorporation within different levels is critical to digest the complex processes and mechanisms of the important elements involved in the study area. Moreover, leveraging such incorporations in design does not bring local benefits right away; it generates additional services long after the design is completed and extends the services to surrounding areas.

In the "performance evaluation" step, we identify evaluation measures by considering how vulnerable or resilient the system is. In K phase, resources become distributed and sequestered to separate areas with high potential of change. With consistent growth and distribution of resources, systems will become vulnerable to collapse in the case of extreme and rigidity [88]. "Performance evaluation" is to evaluate the resilience of systems, especially the current performance from $\mathrm{K}$ to $\Omega$ to find out the underlying reasons why systems collapse. A good example can be found in the study by Loures et al. [109]. They combine multiple approaches (including scientific sample survey, statistical analysis and geographical analysis using GIS) to evaluate how sodium exchange capacity of irrigated and rainfed soils affects agricultural systems. This study investigates the performance of cultural systems practiced (irrigated versus rainfed) to analyze the deterioration of soils. Resilience also suggests continual learning over time through systems' changes and experience, which demonstrates the necessity for participants to constantly take the evaluation measures into consideration during all geodesign processes.

In "scenario creation," we explore possible innovations by modeling and simulation to reorganize from current disturbed state and to design for future conditions [87]. This step is to stimulate emergence the recovery of the systems from $\Omega$ phase (release / creative destruction) to reorganization ( $\alpha$ phase). According to Goldstein [103], emergence is "the arising of novel and coherent structures, patterns and properties during the process of self-organization in complex systems." Referred to as spontaneous order (in the social sciences), self-organization/reorganization is a process where some form of order emerges from interactions within a previously disordered system. Using geodesign processes, the nature of complex systems can be assessed by investigating how changes in one part affect the others and the behavior of the whole. Thus, systems modeling and simulation can analyze the dynamics and facilitate the emergence of a complex system, which reveals more interactions within the system, increases more options for solutions and ultimately enhances final decisions $[87,104,105]$. The classification of scenarios should be defined by the objectives of the project through effective communications of people from different perspectives. Scenarios enable the evaluation of and comparison between potential future conditions [26].

"Impact assessment" investigates the feedback loops underlying the changes from the scenarios and responds positively to feedback through appropriate design strategies. After systems progress 
from release to reorganization, uncertainty suddenly increases from formal chaotic behavior [88]. To deal with uncertainties, we evaluate the impact of scenarios by restrictions and regulations in a broader context for the transition from $\alpha$ to $r$ phase. We should also explore what new structures, patterns and properties of landscape might emerge from the system's self-organization during the changes. In this process, feedback from stakeholders and communities is significant to facilitate assessment.

The integrated framework with its general form functions as a metaphor. It demonstrates dynamic tendencies of a landscape system with an inspiring design process in between each dynamic phase. Multiple participants (stakeholders, designers, planners, communities) build their actions based on their understandings and roles. The four phases of the adaptive cycle may overlap except the transition from $\mathrm{K}$ to $\Omega$ [110]. The sequence of the design steps is not always linear and straight forward in practice.

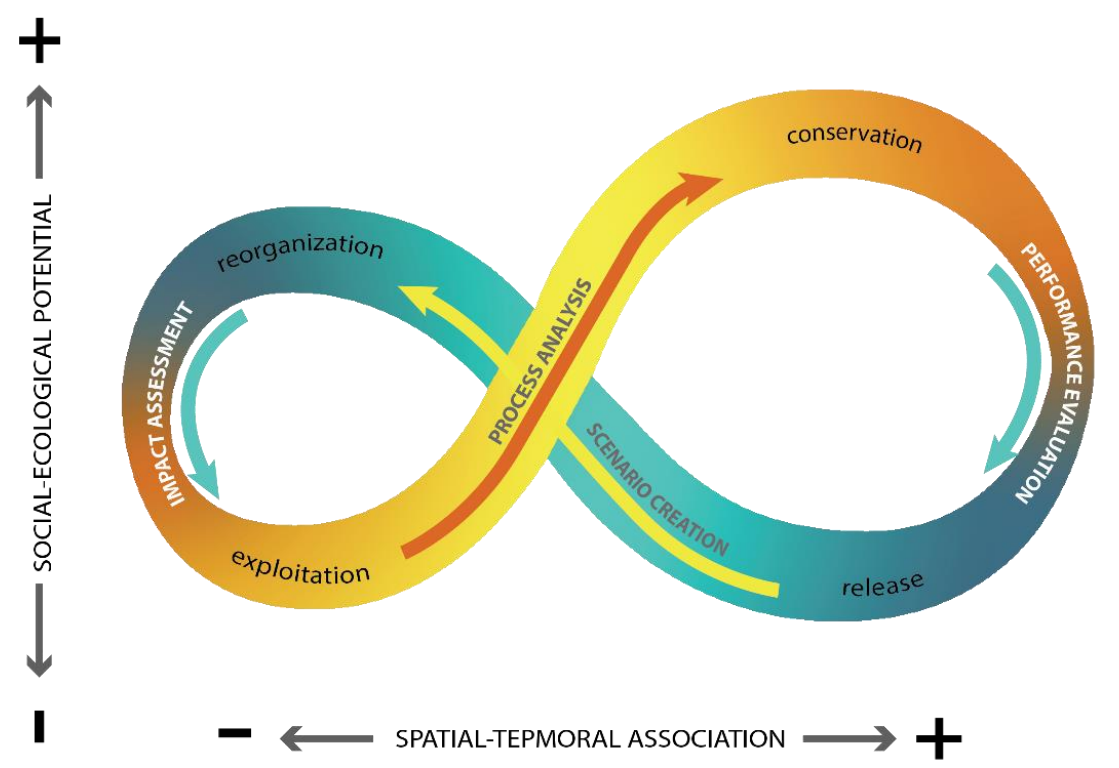

Figure 3. An integrated heuristic framework for landscape architecture by integrating geodesign and the adaptive cycle.

\section{Three Dimensions of the Integrative Framework}

We have presented key aspects of geodesign and integrated it with the adaptive cycle of ecological systems theory to develop a conceptual framework. In this section, we elaborate on the three dimensions of the framework to guide the responses of landscapes, ecosystems and people toward resilience and sustainability.

Gunderson [88] illustrate three dimensions of the adaptive cycle: potential, connectedness and resilience, in which all changes/dynamics are reflected. Understanding changes/dynamics is the key to explore, quantify, analyze and make decisions of any systems. Potential indicates the possibility of change for futures or other systems, which is an internal attribute of the aggregated resources. Connectedness refers to the degree of relatedness among controlling variables. Resilience is the capacity to withstand the influence of a massive disturbance (disaster, war), or a changing circumstance (climate, economics) while maintaining its current functions [77]. In landscape architecture, we use the three terms in a broader sense, which may represent different aspects in different contexts. For example, in a natural landscape, potential refers to the potential from the resources of biomass and nutrients. In an urban landscape, social potential could also be from people's relationships, skills, mutual trust and so forth.

A coupled human-environment system is a combination of many interconnected landscape features. Understanding these connections can help us to adapt, transform and persist under 
constantly changing conditions [111]. An urban system is characterized by temporally dynamic and spatially heterogeneous landscapes whose components and interrelations are profoundly influenced by the interactions of coupled human-environment systems [26,112]. The relations among three dimensions are illustrated in Figure 4. The diagram describes our integrated framework as a centric process that influences and is influenced by these elements and their interconnections. Resilience of the coupled human-environment system is divided into two separate pieces. Variables within human and environment systems should be organized into a nested hierarchical structure to facilitate geodesign analysis. Our framework determines the resilience of human and environment systems using the measures of social-ecological potential and spatial-temporal association. Elements interact through social-ecological processes and spatial-temporal patterns within a multi-scale holistic system. Both spatial (local-regional-national) and temporal (year-decade-century) scales should be taken into consideration.

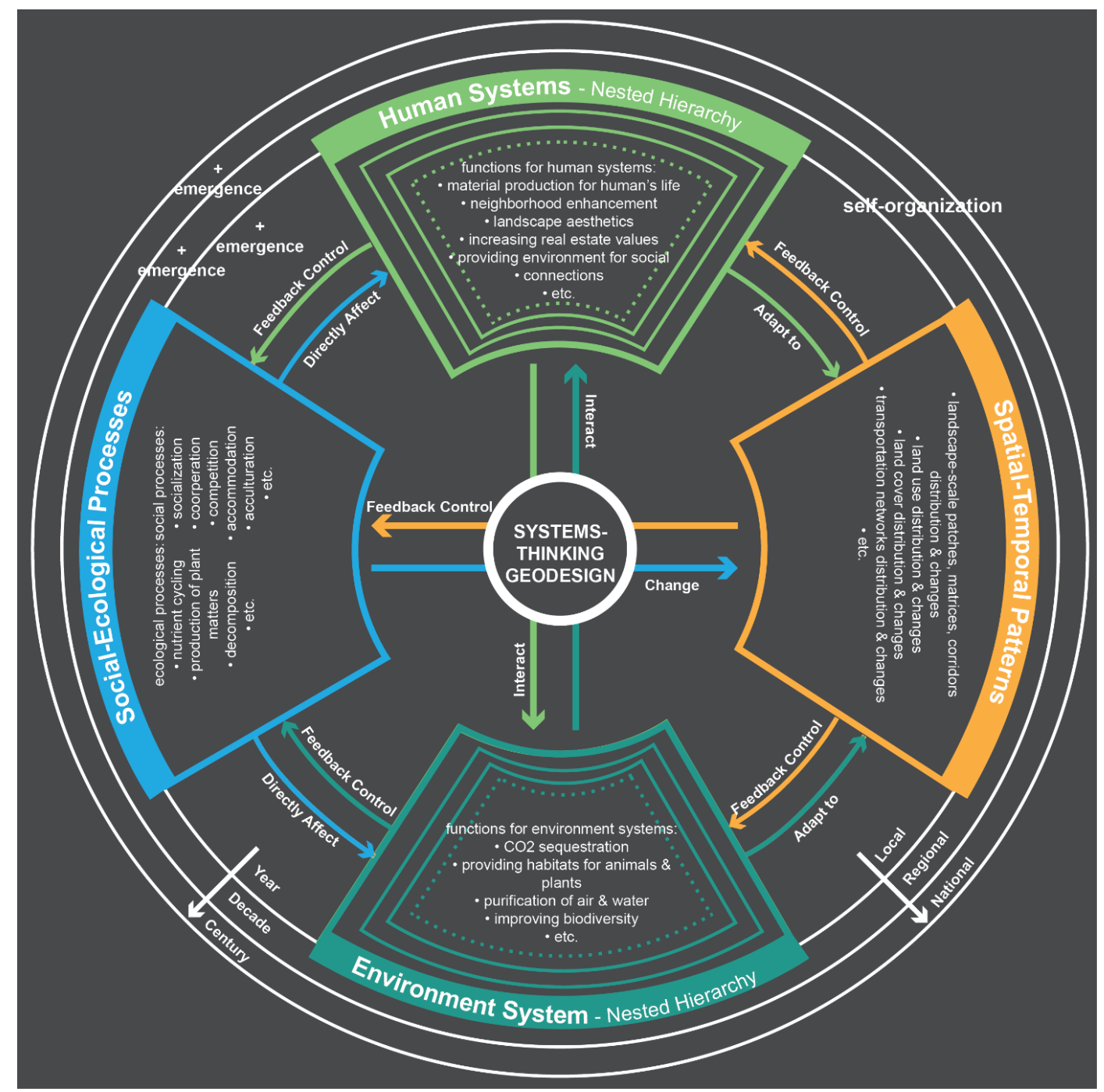

Figure 4. A diagram of the relationships among the integrated framework and related factors-human systems, environment systems, socio-ecological processes and spatiotemporal patterns.

\subsection{Social-Ecological Potential}

Landscape should not just be treated as a result; rather, the breadth of the complex discourse should be considered a process that is constantly changing its potential with social and ecological practices [113]. Extensive literature has shown that social processes in urban environments have caused a great number of problems in ecosystem processes and vice versa. For example, intensified 
human activities resulting from urbanization are the major causes of urban heat islands [114], eutrophication [115] and greenhouse gas emissions [116].

The potential for social-ecological change can be measured through different methods in different contexts. Ecological potential can be represented by potential energy efficiency. It can be measured by the extraction efficiency of biomass or spatial distribution of energy. Social potential can be represented by networks of social relationships, such as mutual trust, competition, friendship and so forth [117]. In landscape architecture, potential could be utilized and accomplished by innovative design that leverages multiple social-ecological processes, such as nutrient cycling, energy production, social accommodation and so forth (see Figure 4 for a more detailed list). Social and ecological processes profoundly influence each other through altering landscape patterns, for which the urban heat island (UHI) effect is a good example. Because of increasing human accommodations in concentrated urban areas, UHI effects generate higher surface and air temperatures in urban regions than surrounding areas, which influence a number of ecological processes, such as habitat distributions for animals, plants and phenology [118-120]. UHI is related to spatial land cover through a spatially nested hierarchical UHI system that is composed of smaller UHIs in certain urban areas [118,121,122]. Altering the UHI system will ultimately change spatial patterns, such as land use and land cover distributions and landscape patterns and vice versa.

Evidence is mounting that geodesign approaches influence social and ecological processes through social learning, cooperation, opinions, competition/negotiation and acculturation. For instance, researchers have demonstrated that geodesign approaches enhance collaborative and deliberative processes by analyzing people's demands, designing feasible scenarios, evaluating change impacts, and assessing trade-offs between conflicting values. This approach eventually drives urban transformation and affects ecological quality.

Assessing how geodesign processes influence the sustainability of design has been a major research focus recently. As Campagna and Di Cesare [31] note, geodesign aims to achieve sustainable design through a range of integrated processes, including site analysis, design conceptualization, simulation and evaluation, scenario alternation, impact assessment and decision making. From a normative and practical perspective, they found that six processes of the geodesign framework bridged the gap from planning to implementation for the Strategic Environmental Assessment (SEA), which was ratified by the European Directive 2001/42/EC. Without a framework that shows how various methods are connected, methods remain isolated. Cumulative knowledge cannot be applied in real projects. The conceptual framework also highlights the collaboration of environmental, social and economic dimensions. In particular, the social dimension of community participation in geodesign processes has gained great momentum recently thanks to the popularity of interactive participatory techniques, mobile devices with GPS and crowd-sourced data.

\subsection{Spatial-Temporal Association}

Spatial-temporal association is the property to reflect the strength of interconnections that constrict and control internal and external disturbance of the system. A system with high spatial-temporal association is managed by strong internal regulations and processes, which makes the system hard to collapse. This property, for example, can be represented by the intensity of people's control on ecological environment, which can be measured by the spatial value of biodiversity and distribution of landscape habitat [123]. Spatial-temporal association is a significant attribute of landscape patterns, which provide a guidance to quantify and assess the organization and assortment of environment.

The study of spatiotemporal patterns in landscape architecture includes two aspects: the quantification of the structures of landscape compositions, and how they change over space and time. Quantifying spatiotemporal patterns is indispensable for understanding the basic organization of the environment that human beings reside in, as well as for exploring the related driving forces and potential impacts resulting from human intervention in the urban and natural environment. 
First, multiple technologies for geodesign have been developed to depict spatiotemporal landscape patterns for the most elemental relationship in landscape design - the geo-relationship, including basic position, adjacency, proximity and changes over time [124]. For instance, Miller et al. [125] emphasizes the importance of geographic patterns (especially the multi-scale assessment of the patterns) in the geodesign study of transportation system performance, taking traffic congestion as an example that is sorted spatially and temporally based on demographic and cultural factors. Such 2D studies influenced later multi-scale 3D explorations [126,127]. Innovative 3D technologies are well suited to visualize the built environment in urban areas and easily encourage participation of non-designers, including stakeholders and the broader public. Aiming to mitigate climate change impacts (especially the urban heat island effect), Danahy, Mitchell, Feick and Wrigh [126] incorporated 2D and 3D geospatial models to visualize heat island data by integrating small-scale data of regional and local land use and land cover with macro-scale remote sensing climate data. The 3D technologies expand the strategies from horizontal on-surface changes to vertical building-scale interventions, which is significant for vertical urban sustainability that involves buildings, such as urban heat island mitigation, energy saving projects and underground sustainability.

Second, some scholars integrate spatiotemporal patterns and intangible social activities to gain a deeper understanding of more complex and dynamic relationships. Besides quantifying simple and algebraic geo-patterns, more and more studies are exploring incalculable and heuristic relationships between landscape patterns and real-world objects [124]. One example is studying the relationship between the behavior of residents in a neighborhood and the neighborhood's streetscape design or the layout design of available facilities. Such relationships are significant in the geodesign simulation phase to evaluate multiple design alternatives based on social demands and to negotiate under varying circumstances and changes over time. These studies are in line with the complexity theory [128] developed from the systems theory [129]. The complexity theory suggests characterizing and analyzing relationships among different levels of the complex and dynamic systems at multiple spatiotemporal scales, which is essential in sustainable development of coupled human-environment systems [130-132]. Multiple spatio-temporal scales are also indicated in Figure 4, where spatial scales include local, regional and national; and temporal scales are represented by year, decade and century.

Some empirical studies have investigated the relationships among the spatiotemporal patterns of environmental benefits [133,134], social configurations [10] and economic development [135], which compose the three pillars of sustainability in coupled socio-ecological systems. For instance, Waldheim [136] incorporates urban studies and agrarian analysis to explore the relationship between agrarian development on urban structure by investigating spatial-temporal patterns and ecological processes of agricultural production. Of course, the landscape patterns and their impacts on the three pillars vary geographically due to the distinctions in socioeconomic drivers, ecological environments and land use policies [24]. Geodesign, however, as a design approach uses sustainable principles to deal with these complexities through its collaborative framework to adapt to temporal changes and different contexts. A number of geospatial visualization and simulation model technologies, especially Planning Support Systems (PSS) [23], have enhanced our capability to understand spatiotemporal patterns and analyze their relationships with ecological, social and economic development to achieve sustainability.

\subsection{Adding Another Dimension: Resilience of the Coupled Human-Environment Systems}

Most landscape design takes place in an environment that influences both human well-being and natural conditions. Assessing how landscape design affects human and environment systems (also referred to as coupled social-ecological systems, or socio-environmental systems) has been a popular research topic in most sustainability studies for the last decade $[137,138]$. According to the U.S. Environmental Protection Agency, sustainability is generation and maintenance of the conditions that humans' need for survival and well-being, which depend on the natural environment directly or indirectly [139]. It is a concept that requires both recognition of natural ecosystem services and the acceptance of humans' manipulation of the environment to successfully manage the integrated 
holistic human-environment system [140]. Similarly, the Nobel Laureate Ostrom [131] developed a social-ecological system (SES) framework to facilitate sustainability research in multiple disciplines, explaining the use of four core subsystems in a framework to analyze an SES.

Resilience of the coupled systems illustrates the capacity to tolerate disturbance while retaining stability domains. It can be measured by the level of disruption that can be tolerated with its multiple stable states without collapsing [78]. Several attempts have been made to assess the resilience of landscape architecture and its impacts on human and environment systems from different angles. For example, in a transportation planning project, Miller, Witlox and Tribby [125] use a geodesign concept (coupling proposal generation with impact simulations) to generate a framework and multidimensional indicators for constructing livable and sustainable communities that promote social (encouraging safe and reliable transportation choices, supporting community revitalization, increasing safe and walkable neighborhoods, promoting human health), economic (enhancing affordable and equitable housing, promoting economic competitiveness) and environmental (improving air quality) aspects of people's lives and related environments.

However, understanding and creating sustainable designs should not only consider how a design approach affects these systems but also how the mutual relationships of these systems change over time. Using ecological systems thinking, we aim to highlight the main relations between human and environment systems and to understand the pattern of systems' behaviors over time through the stock-and-flow diagram (Figure 5). The stock-and-flow diagram is a simple modeling method to show all complex and dynamic behaviors in a system when flows accumulate in stocks and generate feedback to change the stocks [26]. A stock variable represents an entity that is accumulated by inflows and depleted by outflows over time. It can only be changed by flows and measured at one specific time. A flow variable is measured as rate or speed (per unit of time) over an interval of time. In coupled human-environment systems, the two stocks are human and environment systems. They are interconnected by three kinds of flows: social needs, economic controls and ecological processes (e.g., ecological capital's regeneration rates). As the three pillars of sustainability, these flows influence the dynamics of the holistic human-environment system. At the same time, the changes of the two systems also conduct feedback controls through flows on social, economic and ecological elements within the systems. Ultimately, several feedback loops are generated as closed chains of casual relations from the stocks [26]. In order to achieve resilience, the feedback loops should be balanced through equilibrating and goal-seeking the structures of systems.

Numerous studies have demonstrated that geodesign reorganizes ecological, economic and social objectives to improve the long-term health of environment systems and the vitality of human systems [33,141]. For example, Slotterback, Runck, Pitt, Kne, Jordan, Mulla, Zerger and Reichenbach [25] have particularly noted the significance of the geodesign approach in agricultural landscape that facilitates the creation of multifunctional landscapes that not just produce food, fiber, fuel and aesthetic value to human systems, but also provide ecosystem services such as $\mathrm{CO}_{2}$ sequestration, habitat for animals and plants and purification of air and water. Flaxman [8] also states that geodesign allows users to incorporate multiple kinds of information for multifunctional landscape analysis, scenarios generation and evaluation; to make changes for multiple ecosystem services; and to simulate the social, economic and ecological impacts of these landscape changes in real-time evaluative feedback loops. Vaz [142] provides a systemic vision of regional science that highlights the importance of humans in making changes of environment to gain sustainability. Geodesign also addresses the conflicts among the three pillars of sustainability in coupled human-environment systems. For example, Huang and Zhou [32] describes geodesign as a comprehensive design-oriented ecological method that addresses the conflict between the ecological conservation of wildlife habitat and economic tourism development. Geodesign provides a simulation platform where overlaid maps show both the constraints and the opportunities of these conflicts. 


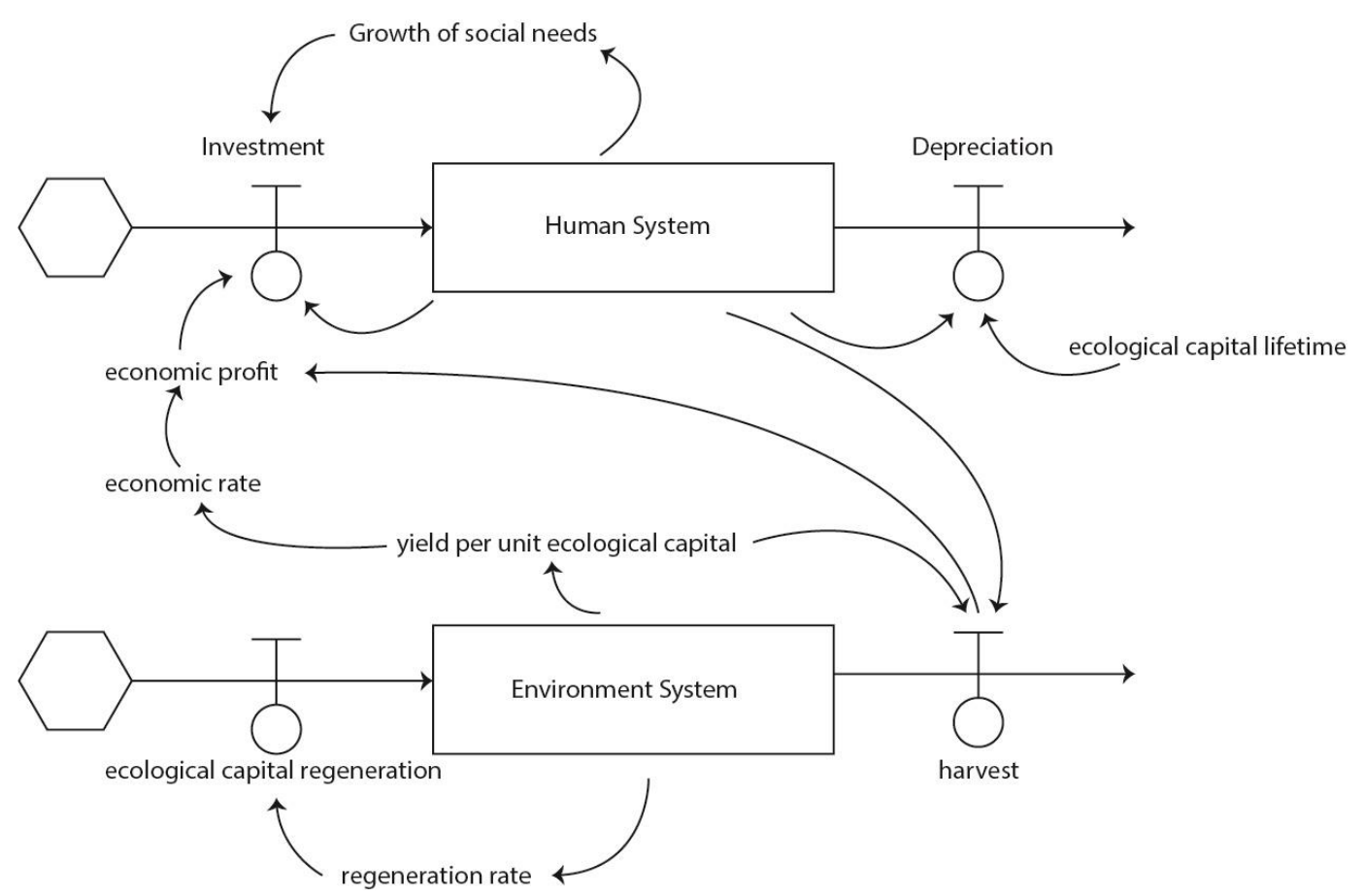

Figure 5. A stock-and-flow diagram of systems thinking illustrating the relationships between human and environment systems-human systems with its reinforcing growth loop constrained by environment systems. Human and environment systems-representing the accumulations of material or information that has built up within its own system over time-are the two stocks (or subsystems) of the larger-scale integrated holistic system. The quantities of the two stocks change over time through the actions of flows, which are influenced directly or indirectly by each other's feedback loops. Thus, understanding and creating the sustainable design should not only consider how design affects these subsystems but also how their interrelationships change in time.

\section{Discussion}

\subsection{Major Findings and Contributions}

This framework extends the reach of geodesign into multiple fields, including sustainable development, urban studies, landscape architecture and urban planning. This framework will encourage more scholars in these fields to understand the complexities of sustainability by integrating ecological systems thinking and geodesign. It guides scholars with systemic processes and comprehensive interconnections rather than fragmented ideas. This framework identifies the interconnections between geodesign approaches and elements of human-environment systems. It explains how geodesign approaches explore social-ecological processes and landscape patterns to achieve landscape-based resilience. In contrast to site-specific design solutions, this framework provides a systematic approach that can be used at multiple scales both spatially and temporally.

\subsection{Implications}

This framework presented in this paper invites future scholars, designers and planners to look beyond the boundaries of the project and embed geodesign approaches and systems' elements into multi-scale, multi-level, nested human-environment systems. For landscape architecture, this framework provides guidance about how to use geodesign process with ecological systems approach at multiple scales and dimensions, rather than individual design ideas for specific sites. For sustainable management, this framework invites managers to identify social-ecological and spatial-temporal dimensions to move beyond the boundaries of industries, firms or products to find a broader spectrum of opportunities. In the field of policy, especially environmental policy, policy analysts can use this 
framework to study existing interventions and their relations with coupled social-ecological systems to prevent dangerous combinations of policies across scales.

Future research should continue to co-opt ideas and approaches from other disciplines for geodesign purposes $[23,125]$. In practice, studies that assess different landscape forms and patterns should be assessed based on their local contexts. We need to adapt and examine the implementation of the general geodesign framework into more diverse research fields. In technological development, some scholars note an opportunity to develop shared code to mutually understand urban values for democratically managed cities, more equitable societies and sustainable futures [37,143]. Related technology development may occur by advancing Crowdsourcing, Social Media Geographic Information (SMGI) and WebGIS [63,144]. Besides advocating and accommodating public engagement, modern technologies also provide rich support for incorporating sketching and computer modeling in the interface at different scales, which may facilitate scenario modeling and influence the scope and style of the geodesign experience $[124,145]$.

\subsection{Gaps and Prospects}

Although we were able to identify a comprehensive framework for landscape architecture, we acknowledge that there are challenges and gaps: (i) theoretical gaps-operationalizing the framework is difficult because it involves complex systems and dynamic processes. (ii) practical gaps-there are challenges within geodesign collaborations in coping with the differences between disparate contexts and groups of people with different backgrounds and its inherent multidisciplinarity makes the process challenging for professional practice; (iii) technology challengers-there are challenges in adapting geodesign tools and models from disparate sources.

We explain each gap in more detail and propose some theoretical, practical and technological perspectives which might inform future studies in the following sections.

\subsubsection{Theoretical Gaps and Prospects}

This paper provides a new point of ecological systems thinking as a theoretical basis for geodesign studies. However, the basic systems-thinking theories of stocks, flows, feedback loops, dynamic equilibrium and so forth have not yet been elaborated in geodesign theoretical and practical studies. An incomplete understanding makes people neglect the feedback loops that are critical across subsystems, which may be fatal flaw to the whole system. It may also result in the misuse of geodesign processes in contexts where they do not belong. Ecological systems thinking helps people to comprehensively understand the geodesign framework, to realize the highly complex and dynamic reality of systems and to safeguard multidisciplinary collaboration that strengthens sustainable practices.

Future theoretical research should borrow ideas and approaches from other disciplines related to systems thinking for different purposes in different geodesign phases [23,125]. At the same time, we acknowledge the importance of adapting these approaches to local contexts. As we describe in this paper, a few approaches have been used to assist the geodesign process. For example, the Multi-Actor MultiCriteria Analysis (MAMCA) is used for maintaining and incorporating various stakeholders' viewpoints throughout the geodesign process [125]. More approaches in diverse disciplines should be explored and integrated in geodesign studies if appropriate. They should also be examined in different contexts and summarized holistically.

\subsubsection{Practical Gaps and Prospects}

There is a tension between the geodesign framework's effectiveness regarding common issues and site-specific actions. Studies that assess different landscape forms and patterns should be assessed differently based on their context. We need to adapt and examine the implementation of the general geodesign framework into diverse research fields. For example, Perkl [146] adapts the general geodesign framework into a hybrid geodesign and connectivity conservation framework to be 
used in corridor connectivity conservation with locally-specific considerations and design processes. More research is needed to discover how to adapt a general geodesign framework in different contexts.

Some papers also discuss the practical failures of long-term achievement due to ignorance in ecological and social monitoring [32] and the trade-offs between studies' depth, breadth and execution speed [147]. These practical gaps involve integrating multiple spatiotemporal scales. Here, we recommend that future research test the transferability of these proposed approaches in different contexts and scales and identify their limitations and potential throughout longer time periods. Future research should proactively broaden the extent of geodesign studies to larger territories (especially developing countries with pressing design issues and data-scarce environment) and more industries (agriculture, infrastructure construction, mining, forestry, etc.).

\subsubsection{Technological Gaps and Prospects}

Some studies raise concerns regarding adapting geodesign tools in data-scarce, rapidly-changing environments $[32,144]$. Some also address the issue of geodesign understandability to broaden public participation [37,143]. Li and Milburn [4] note the problem of integrating human creativity with digital codes in the interface [4]. Longley, Goodchild, Maguire and Rhind [29] demonstrates the privacy problems of data with geographic information. He also discerns the lack of interoperability among model codes from different sources to be integrated for implementation [9]. Finally, Ervin [22] points out the likelihood of counterproductive, destructive and unwanted interactions from the combination of different technologies. These technology concerns are essential for the evolution of computer-mediated geodesign. Moving beyond the technological aspect of geodesign, however, we need to rethink the following questions: How will technology shape the geodesign process [148]? What role does technology play in geodesign's future and what are the actual essentials of geodesign? We argue that systemic thinking in geodesign is the most crucial piece of geodesign. Future studies should seek to understand this way of thinking and utilize it in practice.

Furthermore, our paper also reveals some unexploited opportunities. Some scholars note an opportunity to develop shared code to mutually understand urban values for democratically managed cities, more equitable societies and sustainable futures $[37,143]$. Related technology development may occur by advancing Crowdsourcing, Social Media Geographic Information (SMGI) and WebGIS $[63,144]$. Besides advocating and accommodating public engagement, modern technologies also provide rich support for incorporating sketching and computer modeling in the interface at different scales, which may facilitate scenario modeling and influence the scope and style of the geodesign experience [124,145].

\section{Conclusions}

Until quite recently, several parallel approaches and principles to geodesign evolved with little communication. During the past decade, an increasing number of scholars and practitioners have begun to develop a more general (and practical) conceptualization of geodesign [1,146,149]. Although geodesign as a practice is on the rise, a comprehensively operational and theoretically strong definition has yet to be established. To date, geodesign has been defined by simply combining different concepts based on personal or project-based objectives or contexts. However, the environment that people reside in, especially urban areas, are complex, adaptive and spatially heterogeneous systems with dynamic processes and complicated interconnections [24]. We therefore should contemplate geodesign more comprehensively, which can be achieved by incorporating ecological systems thinking.

This paper examined influential geodesign based studies to identify major perspectives of geodesign, achieve a range of definitions of geodesign and integrate core concepts of systems thinking to generate a new framework for landscape architecture. In order to achieve true resilience and sustainability, we need approaches that: comprehensively identify the variables of coupled human-environment systems; explore the relationships between social, economic and ecological processes; and alter spatiotemporal patterns in multi-scale landscapes. 
Supplementary Materials: The following are available online at http:/ /www.mdpi.com/2071-1050/10/9/3306/ s1, Table S1: List of the selected papers with some of the key elements, Table S2: Steinitz's geodesign framework and corresponding concepts of systems thinking, Material S3: methodology.

Author Contributions: Y.G. and B.D. contributed substantially to the research design, analysis and writing of this paper. L.L. contributed to writing-review and editing.

Funding: This research received no external funding.

Conflicts of Interest: The authors declare no conflict of interest.

\section{References}

1. Steinitz, C. A Framework for Geodesign; ESRI Press: Redlands, CA, USA, 2012; Chapter 1, pp. 3-18.

2. Flaxman, M. Geodesign: Fundamental principles and routes forward. In Proceedings of the GeoDesign Summit 2010, Esri's Redlands, CA, USA, 6-8 January 2010.

3. Miller, W.R. Introducing Geodesign: The Concept; ESRI Press: Redlands, CA, USA, 2012.

4. Li, W.; Milburn, L.-A. The evolution of geodesign as a design and planning tool. Landsc. Urban Plan. 2016, 156, 5-8. [CrossRef]

5. Steiner, F.R.; Shearer, A.W. Geodesign—Changing the world, changing design. Landsc. Urban Plan. 2016, 1-4. [CrossRef]

6. Kunzmann, K. Geodesign: Chance oder gefahr? Inf. Raumentwickl. 1993, 7, 389-396.

7. Dangermond, J. Geodesign and gis-designing our futures. Peer Reviewer Proceedings of Digital Landscape Architecture, Anhalt University of Applied Science, Berlin, Germany; 2010. Available online: http:/ /www. kolleg.loel.hs-anhalt.de/landschaftsinformatik/436.html (accessed on 26 August 2018).

8. Flaxman, M. Geodesign: Fundamental principles. In Proceedings of the Geodesign Summit, Redlands, CA, USA, 6-8 January 2010. Available online: https:/ / www.esri.com/videos/watch?videoid=106\&isLegacy= true (accessed on 26 August 2018).

9. Goodchild, M.F. Towards geodesign: Repurposing cartography and GIS? Cartogr. Perspect. 2010, 7-22. [CrossRef]

10. Deal, B.; Petri, A.; Pan, H.; Goldenberg, R.; Kalantari, Z.; Cvetkovic, V. Socio-Environmental Resilience and Complex Urban Systems Modeling. In Proceedings of the EGU General Assembly Conference, Vienna, Austria, 23-28 April 2017; p. 18478.

11. Eikelboom, T.; Janssen, R. Comparison of geodesign tools to communicate stakeholder values. Group Decis. Negotiat. 2015, 24, 1065-1087. [CrossRef]

12. Orland, B. The path to geodesign! The family car of digital landscape architecture? Digit. Landsc. Arch. 2015, $32-41$.

13. Rivero, R.; Smith, A.; Ballal, H.; Steinitz, C. Promoting Collaborative Geodesign in a Multidisciplinary and Multiscale Environment: Coastal Georgia 2050, USA; Peer Reviewed Proceedings of Digital Landscape Architecture: Bernburg, Germany, 2015; pp. 42-58.

14. Foster, K. Geodesign parsed: Placing it within the rubric of recognized design theories. Landsc. Urban Plan. 2016, 156, 92-100. [CrossRef]

15. Eikelboom, T.; Janssen, R.; Stewart, T.J. A spatial optimization algorithm for geodesign. Landsc. Urban Plan. 2015, 144, 10-21. [CrossRef]

16. Deal, B.; Petri, A.; Pan, H.; Timm, S. 14 big data, socio-environmental resilience and urban systems planning support. In Big Data Regional Science; Routledge: Abingdon, UK, 2017.

17. Deal, B.; Pan, H.; Timm, S.; Pallathucheril, V. The role of multidirectional temporal analysis in scenario planning exercises and planning support systems. Comput. Environ. Urban Syst. 2017, 64, 91-102. [CrossRef]

18. Brown, T. Change by Design; HarperBusiness: Toronto, ON, Canada, 2009.

19. Steinitz, C. On change and geodesign. Landsc. Urban Plan. 2016, 156, 23-25. [CrossRef]

20. Eikelboom, T.; Janssen, R. Collaborative use of geodesign tools to support decision-making on adaptation to climate change. Mitig. Adapt. Strateg. Glob. Chang. 2017, 22, 247-266. [CrossRef] [PubMed]

21. Steinitz, C. A framework for geodesign. Esri Press 2012, 1, 3-18.

22. Ervin, S.M. Technology in geodesign. Landsc. Urban Plan. 2016, 156, 12-16. [CrossRef]

23. Campagna, M. Metaplanning: About designing the geodesign process. Landsc. Urban Plan. 2016, 156, 118-128. [CrossRef] 
24. $\mathrm{Wu}, \mathrm{J}$. Urban ecology and sustainability: The state-of-the-science and future directions. Landsc. Urban Plan. 2014, 125, 209-221. [CrossRef]

25. Slotterback, C.S.; Runck, B.; Pitt, D.G.; Kne, L.; Jordan, N.R.; Mulla, D.J.; Zerger, C.; Reichenbach, M. Collaborative geodesign to advance multifunctional landscapes. Landsc. Urban Plan. 2016, 156, 71-80. [CrossRef]

26. Meadows, D.H. Thinking in Systems; Chelsea Green Publishing: White River Junction, VT, USA, 2008; pp. 77-78.

27. McHarg, I.L.; Mumford, L. Design with Nature; American Museum of Natural History: New York, NY, USA, 1969.

28. McHarg, I.L. A Quest for Life: An Autobiography; John Wiley \& Sons: Hoboken, NJ, USA, 1996.

29. Longley, P.A.; Goodchild, M.F.; Maguire, D.J.; Rhind, D.W. Geographic Information Science and Systems; John Wiley \& Sons: Hoboken, NJ, USA, 2015.

30. Steinitz, C. Meaning and the congruence of urban form and activity. J. Am. Inst. Plan. 1968, 34, $233-248$. [CrossRef]

31. Campagna, M.; Di Cesare, E.A. Geodesign: Lost in regulations (and in practice). In Smart Energy in the Smart City; Springer: Cham, Switzerland, 2016; pp. 307-327.

32. Huang, G.; Zhou, N. Geodesign in developing countries: The example of the master plan for wulingyuan national scenic area, china. Landsc. Urban Plan. 2016, 156, 81-91. [CrossRef]

33. Aina, Y.; Al-Naser, A.; Garba, S. Towards an integrative theory approach to sustainable urban design in saudi arabia: The value of geodesign. In Advances in Landscape Architecture; InTech: Vienna, Austria, 2013.

34. Walliss, J.; Walls, W. A Performative Approach to Geodesign: Conceiving Open Space in a Highly Polluted Beijing; Digital Landscape Architecture Conference ETH Zurich: Zurich, Switzerland, 2014; pp. 21-23.

35. Cross, N. Science and design methodology: A review. Res. Eng. Des. 1993, 5, 63-69. [CrossRef]

36. Langrish, J.Z. The design methods movement: From optimism to darwinism. In Proceedings of the DRS2016: Design + Research + Society Future Focused Thinking, Brighton, UK, 27-30 June 2016.

37. Wilson, M.W. On the criticality of mapping practices: Geodesign as critical GIS? Landsc. Urban Plan. 2015, 142, 226-234. [CrossRef]

38. $\mathrm{Gu}, \mathrm{Y}$. Rejuvenation of the Ditch-Redefining the Landscape of the Embarras River with Integrated Analytical \& Design Approaches. Master's Thesis, University of Illinois at Urbana, Champaign, IL, USA, 2016.

39. Brian Deal, Y.G.; Pan, H. Community, science, and design: Using dynamic spatial simulation models in a three-facet approach to geodesign. In Digital Landscape Architecture-3rd International Digital Landscape Seminar; Northeast University Press: Boston, MA, USA, 2017; pp. 341-355.

40. Simon, H.A. The New Science of Management Decision; Harper \& Brothers: New York, NY, USA, 1960.

41. Asimow, M. Introduction to Design; Prentice-Hall: Upper Saddle River, NJ, USA, 1962.

42. Fogler, H.S.; LeBlanc, S.E.; Rizzo, B.R. Strategies for Creative Problem Solving; PTR Prentice Hall: Englewood Cliffs, NJ, USA, 1995.

43. Kumar, V. 101 Design Methods: A Structured Approach for Driving Innovation in Your Organization; John Wiley \& Sons: Hoboken, NJ, USA, 2012.

44. Ruggeri, D.; Young, D. Community in the information age: Exploring the social potential of web-based technologies in landscape architecture and community design. Front. Arch. Res. 2016, 5, 15-26. [CrossRef]

45. Taylor, N. Urban Planning Theory Since 1945; Sage: Thousand Oaks, CA, USA, 1998.

46. Latour, B. Facing Gaia; Polity Press: Cambridge, UK, 2017.

47. Irvin, R.A.; Stansbury, J. Citizen participation in decision making: Is it worth the effort? Public Adm. Rev. 2004, 64, 55-65. [CrossRef]

48. Putnam, R.D. Bowling alone: America's declining social capital. J. Democr. 1995, 6, 65-78. [CrossRef]

49. Hester, R.T., Jr. A refrain with a view [participation with a view]. Places 1999, 12, 13-25.

50. Loukaitou-Sideris, A. The byzantine-latino quarter: Creating community in los angeles' inner city. disP Plan. Rev. 2000, 36, 16-22. [CrossRef]

51. Zhou, X.; Yu, W.; Sullivan, W.C. Making pervasive sensing possible: Effective travel mode sensing based on smartphones. Comput. Environ. Urban Syst. 2016, 58, 52-59. [CrossRef]

52. Moran, S.; Perreault, M.; Smardon, R. Finding our way: A case study of urban waterway restoration and participatory process. Landsc. Urban Plan. 2016. [CrossRef] 
53. Wu, C.-L.; Chiang, Y.-C. A geodesign framework procedure for developing flood resilient city. Habitat Int. 2018, 75, 78-89. [CrossRef]

54. Beebeejaun, Y.; Durose, C.; Rees, J.; Richardson, J.; Richardson, L. 'Beyond text': Exploring ethos and method in co-producing research with communities. Community Dev. J. 2013, 49, 37-53. [CrossRef]

55. Fahy, F.; Cinnéide, M.Ó. Re-constructing the urban landscape through community mapping: An attractive prospect for sustainability? Area 2009, 41, 167-175. [CrossRef]

56. Manzini, E.; Rizzo, F. Small projects/large changes: Participatory design as an open participated process. CoDesign 2011, 7, 199-215. [CrossRef]

57. Levrel, H.; Etienne, M.; Kerbiriou, C.; Page, C.L.; Rouan, M. Co-modeling process, negotiations, and power relationships: Some outputs from a MAB project on the island of ouessant. Soc. Nat. Resour. 2009, 22, 172-188. [CrossRef]

58. Videira, N.; Antunes, P.; Santos, R.; Lopes, R. A participatory modelling approach to support integrated sustainability assessment processes. Syst. Res. Behav. Sci. 2010, 27, 446-460. [CrossRef]

59. Fawcett, S.B.; Boothroyd, R.; Schultz, J.A.; Francisco, V.T.; Carson, V.; Bremby, R. Building capacity for participatory evaluation within community initiatives. J. Prev. Interv. Community 2003, 26, 21-36. [CrossRef]

60. Smits, P.A.; Champagne, F. An assessment of the theoretical underpinnings of practical participatory evaluation. Am. J. Eval. 2008, 29, 427-442. [CrossRef]

61. Shaw, A.; Sheppard, S.; Burch, S.; Flanders, D.; Wiek, A.; Carmichael, J.; Robinson, J.; Cohen, S. Making local futures tangible-Synthesizing, downscaling, and visualizing climate change scenarios for participatory capacity building. Glob. Environ. Chang. 2009, 19, 447-463. [CrossRef]

62. Waldheim, C. Landscape as Urbanism: A General Theory; Princeton University Press: Princeton, NJ, USA, 2016.

63. Campagna, M. The geographic turn in social media: Opportunities for spatial planning and geodesign. In International Conference on Computational Science and Its Applications, 2014; Springer: Cham, Switzerland, 2014; pp. 598-610.

64. Pickett, S.T.; Burch, W.R.; Dalton, S.E.; Foresman, T.W.; Grove, J.M.; Rowntree, R. A conceptual framework for the study of human ecosystems in urban areas. Urban Ecosyst. 1997, 1, 185-199. [CrossRef]

65. Zipperer, W.C.; Wu, J.; Pouyat, R.V.; Pickett, S.T. The application of ecological principles to urban and urbanizing landscapes. Ecol. Appl. 2000, 10, 685-688. [CrossRef]

66. Grimm, N.B.; Grove, J.G.; Pickett, S.T.; Redman, C.L. Integrated approaches to long-term studies of urban ecological systems: Urban ecological systems present multiple challenges to ecologists-Pervasive human impact and extreme heterogeneity of cities, and the need to integrate social and ecological approaches, concepts, and theory. AIBS Bull. 2000, 50, 571-584.

67. Wu, J.; Jenerette, G.D.; Buyantuyev, A.; Redman, C.L. Quantifying spatiotemporal patterns of urbanization: The case of the two fastest growing metropolitan regions in the united states. Ecol. Complex. 2011, 8, 1-8. [CrossRef]

68. Agnoletti, M. Rural landscape, nature conservation and culture: Some notes on research trends and management approaches from a (Southern) european perspective. Landsc. Urban Plan. 2014, 126, 66-73. [CrossRef]

69. Forman, R.T. The Urban Region: Natural Systems in Our Place, Our Nourishment, Our Home Range, Our Future; Springer: Berlin, Germany, 2008.

70. Forman, R.T. Urban Regions: Ecology and Planning Beyond the City; Cambridge University Press: London, UK, 2008.

71. Zonneveld, I.S. Land Ecology: An Introduction to Landscape Ecology as a Base for Land Evaluation, Land Management and Conservation; SPB Academic Publishing: The Hague, The Netherlands, 1995.

72. Cerreta, M.; Inglese, P.; Manzi, M.L. A multi-methodological decision-making process for cultural landscapes evaluation: The green lucania project. Procedia-Soc. Behav. Sci. 2016, 216, 578-590. [CrossRef]

73. Simon, H. Public administration in today's world of organizations and markets. PS Political Sci. Politics 2000, 33, 749-756.

74. Johnson, A.R. Spatiotemporal hierarchies in ecological theory and modeling. In GIS and Environmental Modeling: Progress and Research Issues; John Wiley \& Sons: Hoboken, NJ, USA, 1996; pp. 451-456.

75. Giampietro, M. Using hierarchy theory to explore the concept of sustainable development. Futures 1994, 26, 616-625. [CrossRef] 
76. Van Marrewijk, M. Concepts and definitions of csr and corporate sustainability: Between agency and communion. J. Bus. Ethics 2003, 44, 95-105. [CrossRef]

77. Holling, C.S. Resilience and stability of ecological systems. Annu. Rev. Ecol. Syst. 1973, 4, 1-23. Available online: https: / / wwwannualreviewsorg/journal/ecolsys/ (accessed on 26 August 2018). [CrossRef]

78. Deal, B.; Gu, Y. Resilience thinking meets social-ecological systems (sess): A general framework for resilient planning support systems (psss). J. Dig. Landsc. Archit. 2018, 200-207.

79. Norberg, J.; Cumming, G. Complexity theory for a sustainable future; Columbia University Press: New York, NY, USA, 2008.

80. Fiksel, J. Sustainability and resilience: Toward a systems approach. J. Sustain.: Sci., Pract. Policy 2006, 2, 14-21.

81. Folke, C.; Carpenter, S.; Elmqvist, T.; Gunderson, L.; Holling, C.S.; Walker, B. Resilience and sustainable development: Building adaptive capacity in a world of transformations. AMBIO: A J. Hum. Environ. 2002, 31, 437-440. [CrossRef]

82. Godschalk, D.R. Urban hazard mitigation: Creating resilient cities. Nat. Hazard. Rev. 2003, 4, $136-143$. [CrossRef]

83. Zimmerman, R. Social implications of infrastructure network interactions. J. Urban Technol. 2001, 8, 97-119. [CrossRef]

84. Bell, M.A. The five principles of organizational resilience. Gartner Res. 2002. Available online: https: / /www.scribd.com/document/160159276/The-Five-Principles-of-Organizational-Resilience (accessed on 26 August 2018).

85. Rosenfeld, A.; Kak, A. Edge detection. In Digital Picture Processing; Academic Press: Orlando, FL, USA, 1982; pp. 84-112.

86. Bulkeley, H.; Betsill, M. Rethinking sustainable cities: Multilevel governance and the 'urban' politics of climate change. Environ. Politics 2005, 14, 42-63. [CrossRef]

87. Gu, Y.; Deal, B. Coupling systems thinking and geodesign processes in land-use modelling, design, and planning. J. Dig. Landsc. Archit. 2018, 3, 2.

88. Gunderson, L.H. Panarchy: Understanding Transformations in Human and Natural Systems; Island Press: Washington, DC, USA, 2001.

89. Holling, C.S. The resilience of terrestrial ecosystems: Local surprise and global change. In Sustainable Development of the Biosphere; Cambridge University Press: Cambridge, UK, 1986; pp. 292-317.

90. Walker, B.; Holling, C.S.; Carpenter, S.R.; Kinzig, A. Resilience, adaptability and transformability in social-ecological systems. Ecol. Soc. 2004, 9. [CrossRef]

91. Folke, C.; Carpenter, S.R.; Walker, B.; Scheffer, M.; Chapin, T.; Rockström, J. Resilience thinking: Integrating resilience, adaptability and transformability. Ecol. Soc. 2010, 15, 20. [CrossRef]

92. Westley, F.R.; Tjornbo, O.; Schultz, L.; Olsson, P.; Folke, C.; Crona, B.; Bodin, Ö. A theory of transformative agency in linked social-ecological systems. Ecol. Soc. 2013, 18, 27. [CrossRef]

93. Johnson, T.A. Harmonic vocabulary in the music of john adams: A hierarchical approach. J. Music Theory 1993, 37, 117-156. [CrossRef]

94. Wu, J.; Loucks, O.L. From balance of nature to hierarchical patch dynamics: A paradigm shift in ecology. In The Quarterly Review of Biology; The University of Chicago: Chicago, IL, USA, 1995; pp. 439-466.

95. O'Neill, R.V. Hierarchy Theory and Global Change; Oak Ridge National Lab: Oak ridge, TN, USA, 1985.

96. Phillips, J.D. Biogeomorphology and landscape evolution: The problem of scale. In Biogeomorphology, Terrestrial and Freshwater Systems; Elsevier: Amsterdam, The Netherlands, 1995; pp. 337-347.

97. Chrisman, N. Charting the Unknown: How Computer Mapping at Harvard Became Gis; Esri Press: Los Angeles, CA, USA, 2006.

98. Gunderson, L.H. Adaptive dancing: Interactions between social resilience and ecological crises. In Navigating Social-Ecological Systems: Building Resilience for Complexity and Change; Cambridge University Press: Cambridge, UK, 2003; pp. 33-52.

99. Westley, F. Governing design: The management of social systems and ecosystems management. In Barriers and Bridges to the Renewal of Ecosystems and Institutions; Columbia University Press: New York, NY, USA, 1995; pp. 391-427.

100. Börjeson, L.; Höjer, M.; Dreborg, K.-H.; Ekvall, T.; Finnveden, G. Scenario types and techniques: Towards a user's guide. Futures 2006, 38, 723-739. [CrossRef] 
101. Chakraborty, A.; Kaza, N.; Knaap, G.-J.; Deal, B. Robust plans and contingent plans: Scenario planning for an uncertain world. J. Am. Plan. Assoc. 2011, 77, 251-266. [CrossRef]

102. Schoemaker, P.J. Scenario planning: A tool for strategic thinking. Sloan Manage. Rev. 1995, 36, 25.

103. Goldstein, J. Emergence as a construct: History and issues. Emergence 1999, 1, 49-72. [CrossRef]

104. Romero, E.; Ruiz, M.C. Framework for applying a complex adaptive system approach to model the operation of eco-industrial parks. J. Ind. Ecol. 2013, 17, 731-741.

105. Dougherty, D.; Dunne, D.D. Organizing ecologies of complex innovation. Organ. Sci. 2011, 22, $1214-1223$. [CrossRef]

106. Walker, B.; Salt, D. Resilience Thinking: Sustaining Ecosystems and People in a Changing World; Island Press: Washington, DC, USA, 2012.

107. Forrester, J.W. Urban dynamics. IMR; Ind. Manage. Rev. (pre-1986) 1970, 11, 67. [CrossRef]

108. Whiteman, G.; Forbes, B.C.; Niemelä, J.; Chapin III, F.S. Bringing feedback and resilience of high-latitude ecosystems into the corporate boardroom. AMBIO J. Hum. Environ. 2004, 33, 371-376. [CrossRef]

109. Loures, L.; Gama, J.; Nunes, J.R.; Lopez-Piñeiro, A. Assessing the sodium exchange capacity in rainfed and irrigated soils in the mediterranean basin using GIS. Sustainability 2017, 9, 405. [CrossRef]

110. Gunderson, L.H.; Holling, C.S. Panarchy: Understanding Transformations in Systems of Humans and Nature; Island Press: Washington, DC, USA, 2002.

111. Williams, A.; Kennedy, S.; Philipp, F.; Whiteman, G. Systems thinking: A review of sustainability management research. J. Clean. Prod. 2017, 148, 866-881. [CrossRef]

112. Deal, B.; Kim, J.H.; Hewings, G.J.; Kim, Y.W. Complex urban systems integration: The leam experiences in coupling economic, land use, and transportation models in Chicago, IL. In Employment Location in Cities and Regions; Springer: Berlin/Heidelberg, Germany, 2013; pp. 107-131.

113. Hayek, U.W.; von Wirth, T.; Neuenschwander, N.; Grêt-Regamey, A. Organizing and facilitating geodesign processes: Integrating tools into collaborative design processes for urban transformation. Landsc. Urban Plan. 2016, 156, 59-70. [CrossRef]

114. Rizwan, A.M.; Dennis, L.Y.; Chunho, L. A review on the generation, determination and mitigation of urban heat island. J. Environ. Sci. 2008, 20, 120-128. [CrossRef]

115. Jiang, L.; Young, M.H.; Hardee, K. Population, urbanization and the environment. World Watch 2008, 21, 34-39.

116. Satterthwaite, D. Cities' contribution to global warming: Notes on the allocation of greenhouse gas emissions. Environ. Urban. 2008, 20, 539-549. [CrossRef]

117. Berkes, F.; Folke, C. Back to the future: Ecosystem dynamics and local knowledge. In Panarchy: Understanding Transformations in Human and Natural Systems; Gunderson, L.H., Holling, C.S., Eds.; Island Press: Washington, DC, USA, 2002.

118. Oke, T.R. The energetic basis of the urban heat island. Q. J. R. Meteorol. Soc. 1982, 108, 1-24. [CrossRef]

119. Voogt, J.A. Urban Heat Island; Scientific Research Publishing: Wuhan, China, 2000.

120. Grimm, N.B.; Faeth, S.H.; Golubiewski, N.E.; Redman, C.L.; Wu, J.; Bai, X.; Briggs, J.M. Global change and the ecology of cities. Science 2008, 319, 756-760. [CrossRef] [PubMed]

121. Chen, X.-L.; Zhao, H.-M.; Li, P.-X.; Yin, Z.-Y. Remote sensing image-based analysis of the relationship between urban heat island and land use/cover changes. Remote Sens. Environ. 2006, 104, 133-146. [CrossRef]

122. Li, J.-J.; Wang, X.-R.; Wang, X.-J.; Ma, W.-C.; Zhang, H. Remote sensing evaluation of urban heat island and its spatial pattern of the shanghai metropolitan area, china. Ecol. Complex. 2009, 6, 413-420. [CrossRef]

123. Carpenter, S.R.; Ludwig, D.; Brock, W.A. Management of eutrophication for lakes subject to potentially irreversible change. Ecol. Appl. 1999, 9, 751-771. [CrossRef]

124. Ervin, S. A System for Geodesign; Digital Landscape Architecture, Anhalt University of Applied Science: Köthen, Germany, 2011; pp. 145-154.

125. Miller, H.J.; Witlox, F.; Tribby, C.P. Developing context-sensitive livability indicators for transportation planning: A measurement framework. J. Transp. Geogr. 2013, 26, 51-64. [CrossRef]

126. Danahy, J.; Mitchell, J.; Feick, R.; Wrigh, R. Multi-Scale 3D Geovisualization of Urban Heat Island Data for Planning Dialogue in Toronto; Emerging Issues, Challenges and Opportunities in Urban E-Planning; University of Lisbon: Lisbon, Portugal, 2015; pp. 166-187.

127. Trubka, R.; Glackin, S.; Lade, O.; Pettit, C. A web-based 3D visualisation and assessment system for urban precinct scenario modelling. ISPRS J. Photogramm. Remote Sens. 2016, 117, 175-186. [CrossRef] 
128. Burns, T.E.; Stalker, G.M. The Management of Innovation; Tavistock: London, UK, 1961.

129. Von Bertalanffy, L. General system theory. N. Y. 1968, 41973, 40.

130. Folke, C.; Berkes, F. Linking Social and Ecological Systems; Cambridge University Press: London, UK, 1998.

131. Ostrom, E. A general framework for analyzing sustainability of social-ecological systems. Science 2009, 325, 419-422. [CrossRef] [PubMed]

132. Janssen, M. Complexity and Ecosystem Management: The Theory and Practice of Multi-Agent Systems; Edward Elgar Publishing: Cheltenham, UK, 2002.

133. Mörtberg, U.; Haas, J.; Zetterberg, A.; Franklin, J.P.; Jonsson, D.; Deal, B. Urban ecosystems and sustainable urban development-Analysing and assessing interacting systems in the Stockholm region. Urban Ecosyst. 2013, 16, 763-782. [CrossRef]

134. Goldenberg, R.; Kalantari, Z.; Cvetkovic, V.; Mörtberg, U.; Deal, B.; Destouni, G. Distinction, quantification and mapping of potential and realized supply-demand of flow-dependent ecosystem services. Sci. Total Environ. 2017, 593, 599-609. [CrossRef] [PubMed]

135. Cervero, R. Efficient urbanisation: Economic performance and the shape of the metropolis. Urban Stud. 2001, 38, 1651-1671. [CrossRef]

136. Waldheim, C. Industrial economy and agrarian urbanism. In The Horizontal Metropolis between Urbanism and Urbanization; Springer: Cham, Switzerland, 2018; pp. 47-53.

137. Patten, D.T. The role of ecological wisdom in managing for sustainable interdependent urban and natural ecosystems. Landsc. Urban Plan. 2016, 155, 3-10. [CrossRef]

138. Chen, $\mathrm{X} . ; \mathrm{Wu}, \mathrm{J}$. Sustainable landscape architecture: Implications of the Chinese philosophy of "unity of man with nature" and beyond. Landsc. Ecol. 2009, 24, 1015-1026. [CrossRef]

139. United States Environmental Protection. Learn about Sustainability. Available online: https://www.epa. gov / sustainability / learn-about-sustainability (accessed on 26 August 2018).

140. Xiang, W.-N. Doing real and permanent good in landscape and urban planning: Ecological wisdom for urban sustainability. Landsc. Urban Plan. 2014, 121, 65-69. [CrossRef]

141. Wheeler, S.M. Planning sustainable and livable cities. Sustain. Urban Dev. Read. 1998.

142. Vaz, E. The future of landscapes and habitats: The regional science contribution to the understanding of geographical space. Habitat Int. 2016, 51, 70-78. [CrossRef]

143. Borges, J.; Jankowski, P.; Davis, C.A., Jr. Crowdsourcing for geodesign: Opportunities and challenges for stakeholder input in urban planning. In Cartography-Maps Connecting the World; Springer: Cham, Switzerland, 2015; pp. 361-373.

144. Janssen, R.; Dias, E. A pictorial approach to geodesign: A case study for the lower zambezi valley. Landsc. Urban Plan. 2017, 164, 144-148. [CrossRef]

145. Abukhater, A.; Walker, D. Making smart growth smarter with geodesign. Dir. Mag. 2010, 19.

146. Perkl, R.M. Geodesigning landscape linkages: Coupling GIS with wildlife corridor design in conservation planning. Landsc. Urban Plan. 2016, 156, 44-58. [CrossRef]

147. Flaxman, M. Fundamental issues in geodesign. Dig. Landsc. Arch. 2009, 200, 181-182.

148. Tulloch, D. Relinquishing a bit of control: Questions about the computer's role in geodesign. Landsc. Urban Plan. 2016, 156, 17-19. [CrossRef]

149. Batty, M. Defining Geodesign (= Gis + Design?); Sage Publications: London, UK, 2013.

(C) 2018 by the authors. Licensee MDPI, Basel, Switzerland. This article is an open access article distributed under the terms and conditions of the Creative Commons Attribution (CC BY) license (http:/ / creativecommons.org/licenses/by/4.0/). 